\title{
OS REFLEXOS DO NOVO CÓDIGO DE PROCESSO CIVIL NOS SERVIÇOS NOTARIAIS E DE REGISTRO E AS FORMAS CONSENSUAIS DE SOLUÇÃO DE CONFLITOS
}

\author{
THE NEW REFLECTIONS ON CIVIL PROCEDURE CODE NOTARY \\ SERVICES AND REGISTRATION FORMS AND CONSENSUS OF CONFLICT \\ SETTLEMENT
}

\author{
${ }^{1}$ Sérgio Henriques Zandona Freitas \\ ${ }^{2}$ Marina Araújo Campos
}

\section{RESUMO}

O presente artigo científico tem por objetivo estudar meios alternativos de solução de conflitos, como medidas eficazes para alcançar a paz social e desafogar o Judiciário, pela atuação de notários e registradores. Institutos como a conciliação e a mediação foram prestigiados pelo Novo Código de Processo Civil, sendo essenciais para a efetividade do processo constitucional e do Estado Democrático de Direito, eis que impactam nos direitos fundamentais. Adotar-se-á, como marco teórico, a Teoria Constitucionalista do Processo, na obra de José Alfredo de Oliveira Baracho. Como embasamento e para êxito do presente estudo tem-se a pesquisa bibliográfica e o método dedutivo.

Palavras-chave: Serviços notariais e de registro, Acesso à jurisdição e o novo código de processo civil, Conciliação, mediação e gratuidades

\begin{abstract}
This scientific paper studies alternative means of dispute resolution, such as effective measures to achieve social peace and relieve the judiciary, the role of notaries and registrars. Institutes such as conciliation and mediation were prestigious in the New Code of Civil Procedure, being essential to the effectiveness of the constitutional process and the state of democratic rights, once they have impact on fundamental rights. Will be adopted, as a theoretical framework, the Constitutionalist process Theory, the work of José Alfredo de Oliveira Baracho. As the foundation and success of this study we have the literature and deductive method.
\end{abstract}

Keywords: Notary and registration services, Access to the jurisdiction and the new code of civil procedure, Conciliation, mediation and gratuities

\footnotetext{
${ }^{1}$ Doutor em Direito pela Pontifícia Universidade Católica - PUC, Belo Horizonte, Minas Gerais, (Brasil). Pós-Doutorado pela Universidade do Vale do Rio dos Sinos - UNISINOS, São Leopoldo, Rio Grande do Sul. Assessor Judiciário pelo Tribunal de justiça - TJ, Minas Gerais. E-mail: sergiohzf@ fumec.br

${ }^{2}$ Graduação em Direito pela Universidade Federal de Minas Gerais - UFMG, Belo Horizonte. E-mail: marinaaraujoc@hotmail.com
} 


\section{INTRODUÇÃO}

O presente artigo científico busca investigar os reflexos do Novo Código de Processo Civil (doravante nomeado Novo CPC ou CPC/15) nos serviços notariais e de registro, com destaque para o princípio do acesso à jurisdição e os institutos processuais da conciliação e da mediação.

Para tanto, analisar-se-á a Constituição de 1988, ao assegurar a todos a inafastabilidade da apreciação do conflito de interesses pelo Judiciário, nos termos do artigo $5^{\circ}$, inciso XXXV, como forma de acesso à jurisdição, garantia esta elencada como direito fundamental.

Nesse contexto, fundamental o conhecimento da evolução teórica do Direito Processual até a atual sistemática do Processo e Jurisdição Constitucionais, ponto de partida para a testificação de vários outros institutos processuais no Estado Democrático de Direito.

A temática passa ainda pelo exame do efetivo acesso à jurisdição, sob o olhar da necessária garantia da gratuidade das custas e despesas processuais, o que foi feito no Código de Processo Civil de 2015, bem como em relação aos emolumentos devidos aos notários e registradores.

Além disso, ressaltar-se-á o novo Código de Processo Civil ao reconhecer a eficácia dos meios alternativos de solução de conflitos como medidas eficazes para alcançar a paz social e desafogar o Judiciário, motivo pelo qual os incentiva expressamente. O Conselho Nacional de Justiça, por reconhecer a eficiência destes meios de solução de conflitos, editou a Resolução 125, a qual incentiva a conciliação e a mediação pelos tribunais, a qual é implementada também pelas serventias extrajudiciais, que em alguns estados realizam conciliação e mediação.

O presente estudo pretente, portanto, abordar as consequências das inovações do Novo Código de Processo Civil na atividade notarial e registral, bem como os efeitos destas inovações quanto ao acesso à jurisdição, finalidade de ambos os institutos que serão abordados gratuidades e formas alternativas de solução de conflitos.

Adota-se, como marco teórico, a Teoria Constitucionalista do Processo, contemplada na obra de José Alfredo de Oliveira Baracho. Como embasamento e para êxito do presente estudo tem-se a pesquisa bibliográfica e o método dedutivo.

\section{SERVIÇOS NOTARIAIS E DE REGISTRO}


Os serviços notariais e de registro estão disciplinados no artigo 236 da Constituição da República de 1988 (CR/88), que estabelece que estes serviços são exercidos em caráter privado por delegação do Poder Público. De acordo com o Ministro Carlos Britto, no julgamento da ADI 3.643/RJ1, "são atividades próprias do poder público, pela clara razão de que, se não o fossem, nenhum sentido haveria para a remissão que a Lei Maior expressamente faz ao instituto da delegação a pessoas privadas". Os administrativistas classificam os notários e registradores como agentes públicos em sentido amplo, na medida em que são pessoas físicas que exercem uma função pública, e os classificam como particulares em colaboração com a administração pública (MAZZA, 2014, p. 55).

No julgamento da ação direta de inconstitucionalidade da Lei 4.664 do Rio de Janeiro, o relator Carlos Britto destacou que os notários e registradores exercem atividade jurídica do Estado e não meramente material, a qual é trespassada aos particulares por mediante delegação. No seu voto, o Ministro destaca que esta espécie de delegação não se confunde com os contratos de permissão e concessão de serviços públicos, haja vista que estas modalidades de delegação ocorrem através de contratos administrativos celebrados com pessoas jurídicas ou físicas (em caso de permissão) em virtude de adjudicação em procedimento licitatório, ao passo que os serviços notariais e de registros somente podem ser exercidos por pessoa natural aprovada em concurso público de provas e títulos. O relator continua a diferenciação ao apontar que as concessionárias e permissionárias são fiscalizadas pelo Poder Executivo concedente, enquanto os notários e oficiais de registro são fiscalizados pelo Poder Judiciário (artigo 236 da CR/88) e, por fim, aquelas são remuneradas por tarifas ou preços públicos, enquanto estes são remunerados por emolumentos 2 que possuem a natureza de taxa.

Desde 1984 o Supremo Tribunal Federal possui entendimento firmado quanto à natureza tributária dos emolumentos devidos em virtude da serviços notariais e registrais, eis que segundo este tribunal "as custas e os emolumentos judiciais ou extrajudiciais, por não serem preços públicos, mas sim, taxas, não podem ter seus valores fixados por decreto, sujeitos que estão ao princípio constitucional da legalidade" (RTJ 141/430, julgamento ocorrido em 08/08/1984, Representação 1.094-SP, citado na ADI 1.444-7/PR).

\footnotetext{
${ }^{1} \mathrm{Na}$ ADI 3.643-2 o STF decidiu pela constitucionalidade da Lei 4.664 de 2005 do Rio de Janeiro, que destina a taxa de arrecadação pelo exercício do poder de polícia sobre os notários e registradores para o Poder Judiciário e para Defensoria Pública.

${ }^{2}$ ADI 3.643, voto do Rel. Min. Ayres Britto, julgamento em 8-11-2006, Plenário, DJ de 16-2-2007
} 
O artigo 236, $\S 2^{\circ}$ da Constituição determina a competência da União para fixar as normas gerais sobre os emolumentos, o que foi concretizado pela edição da Lei 10.169/20003, cabendo aos estados editar normas específicas e fixar a tabela de emolumentos 4 a ser observada em seu território. Nos termos da lei federal, os emolumentos devem ser fixados de modo a corresponder ao efetivo custo e à adequada e suficiente remuneração dos serviços prestados e considerando a natureza pública e o caráter social dos serviços notariais e de registro.

A competência para legislar sobre registros públicos é da União (Art. 22, inciso XXV da CR/88), que editou a Lei 6.015/73 e a Lei 8.935/94, a qual disciplina a atividade, bem como a responsabilidade, a contratação de empregados, sanções disciplinares, forma de ingresso, nos termos do comando constitucional.

Os serviços notariais e de registro foram diretamente afetados pelo Novo Código de Processo Civil que, em sua nítida tendência de desjudicialização, atribui às serventias importantes atribuições eficazes na pacificação do conflito, como é o caso das escrituras públicas de inventário, divórcio e união estável. Além disso, a Lei 13.105 reconheceu a ata notarial como elemento de prova e previu expressamente a usucapião extrajudicial, a qual é realizada exclusivamente perante o Oficial de Registro de Imóveis.

Verifica-se, portanto, que as alteraçõs do diploma processual civil visam dar efetividade à garantia constitucional do acesso à jurisdição. A Constituição de 1988 assegura a todos os brasileiros a inafastabilidade da apreciação do conflito de interesses pelo Judiciário, nos termos do artigo $5^{\circ}$, inciso XXXV, como forma de acesso à jurisdição, garantia esta elencada como direito fundamental. $\mathrm{O}$ CPC/15 busca dar efetividade ao acesso à jurisdição ao garantir as gratuidades das despesas processuais e fomentar as formas alternativas de solução de conflitos, na medida em que o acesso à jurisdição deve ser percebido em dimensão material, e não se limita ao direito de petição.

Assim, importante o estudo acerca da concepção de acesso à jurisdição para uma compreensão da função das gratuidades dos emolumentos e demais despesas processuais previstas no Novo CPC e as repercussões da conciliação pelos notários e registradores nas serventias extrajudiciais.

Com efeito, vários atos notariais e registrais decorrem de decisão judicial, como por exemplo o registro da sentença declaratória da usucapião, a averbação do reconhecimento de

\footnotetext{
${ }^{3}$ Art. 236, § $2^{\circ}$ Lei federal estabelecerá normas gerais para fixação de emolumentos relativos aos atos praticados pelos serviços notariais e de registro.

${ }^{4}$ Em Minas Gerais a norma que fixa os emolumentos é a Lei 15.424.
} 
paternidade, o registro da interdição, da ausência. Assim, para favorecer o efetivo acesso à jurisdição o Novo Código de Processo Civil determina, em seu artigo 98, a gratuidade dos emolumentos para as pessoas físicas ou jurídicas com insuficiência de recursos para pagar as custas e despesas processuais.

Alem disso, as formas alternativas de solução de conflitos também constituem meio eficaz de pacificação social, os quais são estimulados no Novo Código de Processo Civil e passam a ser realizados nas serventias extrajudiciais de alguns estados brasileiros, nos termos da Resolução 125 do Conselho Nacional de Justiça.

\section{ACESSO À JURISDIÇÃo}

Antes de abordar os efeitos do Novo Código de Processo Civil nas atividades notariais e de registro, em especial quanto às gratuidades e possibilidade de realização de conciliação ou mediação, é importante definir premissas básicas, como o acesso à jurisdição, seus obstáculos e finalidades do processo.

O acesso à jurisdição, para alguns denominado acesso a justiça, deve ser compreendido não como o direito de ação, restrito ao seu sentido formal de acesso ao Judiciário, mas em sentido material abarcando a proposta de pacificação social e de acesso amplo a serviços, informações e órgãos, em plena garantia dos direitos fundamentais da pessoa humana. $\mathrm{Na}$ definição de Cappelletti e Garth, o "acesso à justiça" é o "sistema pelo qual as pessoas podem reivindicar seus direitos e/ou resolver seus litígios sob os auspícios do Estado" o que se coaduna com as lições do Kasuo Watanable, que seguem transcritas:

O princípio de acesso à justiça, inscrito no n. XXXV do art. $5^{\circ}$, da Constituição Federal, não assegura apenas acesso formal aos órgãos judiciários, e sim um acesso qualificado que propicie aos indivíduos o acesso à ordem jurídica justa, no sentido de que cabe a todos que tenham qualquer problema jurídico, não necessariamente um conflito de interesses, uma atenção por parte do Poder Público, em especial do Poder Judiciário. Assim, cabe ao Judiciário não somente organizar os serviços que são prestados por meio de processos judiciais, como também aqueles que socorram os cidadãos de modo mais abrangente, de solução por vezes de simples problemas jurídicos, como a obtenção de documentos essenciais para o exercício da cidadania, e até mesmo de simples palavras de orientação jurídica. Mas é, certamente, na solução dos conflitos de interesses que reside a sua função primordial, e para desempenhá- la cabe-lhe organizar não apenas os serviços processuais como também, e com grande ênfase, os serviços de solução dos conflitos pelos mecanismos alternativos à solução adjudicada por meio de sentença, em especial dos meios consensuais, isto é, da mediação e da conciliação. (WATANABE, 2008, p 15). 
O acesso à jurisdição em dimensão material, considerando os fundamentos da decisão prolatada e a efetividade por ela alcançada, é o direito fundamental que propicia ao indivíduo a satisfação dos demais direitos, quando, por algum motivo, foi o mesmo privado de seu gozo. Assim, de acordo com o jurista italiano Mauro Cappelletti, o "acesso à justiça” pode ser “encarado como o requisito fundamental - o mais básico dos direitos humanos - de um sistema jurídico moderno e igualitário que pretenda garantir, e não apenas proclamar os direitos de todos.” (CAPPELLETI; GARTH, 2002, p. 11).

A efetividade da decisão judicial, portanto, somente será obtida quando o ato notarial ou registral é praticado, pois é a partir deste momento que o ato passa a ter publicidade e é oponível perante terceiros.

Cappelletti e Garth identificaram três ondas de "acesso à justiça", que podem ser assim identificadas:

\begin{abstract}
O recente despertar de interesse em torno do efetivo acesso à Justiça levou a três posições básicas,ao menos nos países do Mundo Ocidental. Tendo início em 1965, estes posicionamentos emergiram mais ou menos em sequência cronológica. Podemos afirmar que a primeira solução para o acesso - a primeira "onda" desse movimento novo foi a assistência judiciária; a segunda dizia respeito às reformas tendentes a proporcionar representação jurídica para os interesses "difusos",especialmente nas áreas de proteção ambiental e do consumidor;e o terceiro - e mais recente - é que nos propomos a chamar simplesmente de "enfoque de acesso à justiça" porque inclui os posicionamentos anteriores, mas vai muito além deles,representado,desta forma, uma tentativa de atacar as barreiras ao acesso de modo mais articulado e compreensivo. (CAPPELLETTI; GARTH, 2002, p 31).
\end{abstract}

Assim, as ondas de acesso à jurisdição podem ser definidas, em síntese, como a de assistência judiciária, a representação de direitos difusos em juízo e, por fim, como formas alternativas de solução de conflitos. Assim, o Novo Código de Processo Civil, ao ampliar o rol de gratuidades, está de acordo com a primeira onda de acesso à jurisdição identificada pelos autores citados.

O acesso à jurisdição pode ser encarado em três perspectivas, a saber, a do cidadão, a da sociedade e a do juiz. A primeira perspectiva a ser abordada é a do cidadão, para o qual o acesso à jurisdição consiste no direito ver sua questão analisada pelo Estado, ser ouvido por este e, concomitantemente, usufruir satisfatoriamente dos serviços públicos. Para a sociedade, o acesso à jurisdição consiste no direito a uma tutela jurisdicional eficaz, capaz de pacificar com justiça e, finalmente, na perspectiva do juiz, deve o aplicador do direito conceber o 
processo como instrumento para a realização da justiça, não como um fim em si mesmo, motivo pelo qual lhe incumbe a remoção dos obstáculos econômicos e sociais que impedem o efetivo acesso à jurisdição e, por isso, à justiça (SENA, 2010, p 157).

Assim, todas as garantias processuais, tais como do devido processo legal, do juiz natural, da ampla defesa, do contraditório, da igualdade das partes, buscam, precipuamente, garantir ao indivíduo o direito processual constitucional ao acesso à jurisdição, e não apenas ao Judiciário, residindo a diferença no fato de que quando aquele é garantido ocorre a pacificação com justiça. Neste contexto, a efetividade do processo deve ser encarada como sua "aptidão, mediante a observância racional desses princípios e garantias, a pacificar segundo critérios de justiça” (DINAMARCO, 2009, p. 333).

Existe, todavia, uma gama de obstáculos que impede ou limita o acesso universal à jurisdição. O primeiro obstáculo apontado por Cappelletti ao "acesso à justiça" são as elevadas custas processuais (CAPPELLETI; GARTH, 2002, p. 11), o que ensejou a edição da Lei 1060/50 que prevê a isenção de custas judiciais para aqueles que declararem pobres, ou seja, para as partes que não tiverem recursos suficientes para arcar com as despesas do processo sem prejudicar a sua subsistência. O Novo CPC busca solucionar os minimizar estes empecilhos apresentados pelo autor e facilitar a concessão da gratuidade.

O tempo é outro empecilho apontado pelo jurista italiano ao "acesso à justiça", isto porque, segundo afirma, muitas vezes as partes não podem esperar o tempo de tramitação do processo ou a inflação pode repercutir negativamente, diminuindo o valor real da causa (CAPPELLETI; GARTH, 2002, p. 12). Este é um fator que muito atinge as ações em curso no Judiciário brasileiro, principalmente em demandas de caráter alimentar.

Além disso, a morosidade da Justiça é incompatível com a dinâmica vivenciada no mercado capitalista, em que a circulação de riquezas é incessante e volátil, o que não condiz com a necessidade de aguardar anos para a decisão acerca da crise de certeza quanto a um contrato.

A terceira dificuldade apresentada por Cappelletti para o "acesso à justiça" é a aptidão para reconhecer um direito e propor uma demanda, isto porque muitas vezes os indivíduos sequer têm consciência de que seus direitos foram lesados e, não sabem qual o procedimento adequado para discutir judicialmente a lesão (CAPPELLETI; GARTH, 2002, p. 21).

Neste ponto se destaca o direito do consumidor, que muito avançou nos últimos anos, mas ainda existe uma parcela considerável da população que desconhece os instrumentos jurídicos para exercer os seus direitos em casos de vicio ou fato do produto, ou até mesmo em 
casos de abuso de direito. A hipossuficiência técnica e jurídica de considerável parte da população para reconhecer os seus direitos e produzir as respectivas provas, obsta, em muitos casos o acesso à jurisdição. Isto porque, conforme bem mencionado por Cappelletti, o formalismo e a complexidade dos procedimentos judiciais impedem a compreensão plena do jurisdicionado dos atos processuais (CAPPELLETI; GARTH, 2002, p. 22). Neste ponto, imperioso destacar os Juizados Especiais e a Justiça do Trabalho, em especial, que se caracterizam pela informalidade e oralidade, o que minimiza este problema, entretanto, não o elimina.

Assim, embora não exista, nestes dois casos, o excesso de formalismo presentes no rito ordinário comum da Justiça Estadual, o indivíduo que busca a jurisdição em grande parte dos casos, sequer tem conhecimento mínimo dos tramites processuais, o que implica, muitas vezes, na sua marginalização do processo, óbice, portanto, ao acesso à jurisdição.

\section{PROCESSO CONSTITUCIONAL}

O pesquisador e constitucionalista mineiro José Alfredo de Oliveira Baracho (1984, p. 122-126) elucidou, a partir do pioneiro estudo do tema Constituição e Processo, a teoria constitucionalista do processo, acolhida com paridade pelo jurista mexicano Hector FixZamudio - que resplandeceu o tema por meio das várias obras e artigos dedicados ao assunto —, e que, só recentemente, sob a denominação de "modelo constitucional" do Processo, ficou explícito seu desmembramento, nas reflexões de Ítalo Andolina, quando afirma que o processo, em seus novos contornos teóricos na pós-modernidade, apresenta-se como necessária instituição constitucionalizada que, pela principiologia constitucional do devido processo que compreende os princípios da reserva legal, da ampla defesa, da isonomia e do contraditório, converte-se em direito-garantia .

Em verdade, concorda o processualista Aroldo Plínio Gonçalves (2001, p. 148-149), que empresta atualmente ao contraditório o status de princípio constitucional, conforme descrito na obra de Rosemiro Pereira Leal (2014, p. 98-99).

O conceito moderno de Estado Democrático de Direito exige que o legislador, nas sociedades Políticas Democráticas de Direito, uma vez eleito, submeta-se aos princípios do Processo como instituição jurídica balizadora da soberania popular e da cidadania, cujos fundamentos se assentam no instrumento da jurisdição constitucional e esta como atividade 
judicatória dos juízes, de forma legal, preexistente e básica, como única fonte do poder constituinte.

Assim, não é demais reprisar que o processo constitucional tem por fundamento garantir o princípio da supremacia constitucional, possibilitando a efetiva tutela, proteção e fomento dos direitos fundamentais (BARACHO, 2006, v. 383, p. 156).

Para tanto, Ronaldo Brêtas de Carvalho Dias ensina que os direitos fundamentais "são os direitos humanos declarados expressamente no ordenamento jurídico-constitucional" (BRÊTAS DE CARVALHO DIAS, 2004, p. 111). O mesmo autor afirmou ainda que as garantias fundamentais "compreendem as garantias processuais estabelecidas na própria Constituição (processo constitucional) e formadoras de um essencial sistema de proteção aos direitos fundamentais, tecnicamente apto a lhes assegurar efetividade" (BRÊTAS DE CARVALHO DIAS, 2004, p. 111), tais como o mandado de segurança, o habeas corpus, o habeas data, o mandado de injunção, a ação popular e, a mais importante delas, o devido processo legal, informado pelos princípios do juízo natural, do contraditório, da ampla defesa e da indispensabilidade da presença do advogado.

Importante ressaltar que o processo constitucional demanda pressupostos essenciais, dentre eles: o direito à celeridade dos processos, a razoável duração dos pleitos, e as formas de controle constitucional (preventivo, repressivo, direto, repressivo indireto e ocasional); que não podem ser confundidos com diminuição ou eliminação das garantias processuais constitucionais (contraditório, ampla defesa, duplo grau de jurisdição, fundamentação das decisões, direito de prova, instrumentalidade das formas, presença de advogado, dentre outros), sob pena de ferir o princípio do Estado Democrático de Direito.

Aqui vale o destaque na obra de Cattoni de Oliveira (2006, p. 74-75), lembrando lições de José Alfredo de Oliveira Baracho, da importância do "modelo constitucional do processo", estruturado nos princípios do due process, do contraditório, da ampla defesa, do direito à prova, do juízo natural, independente e imparcial, da fundamentação racional das decisões jurisdicionais, da publicidade, da instrumentalidade técnica do processo, da efetividade e da inafastabilidade da tutela jurisdicional.

Assim, o processo constitucional apresenta-se como garantia para a efetivação dos direitos fundamentais e, dentre estes, o próprio Direito à Jurisdição.

\section{JURISDIÇÃO CONSTITUCIONAL}


José Alfredo de Oliveira Baracho ao incentivar o estudo do processo constitucional destaca o instituto da jurisdição constitucional, ao afirmar que: "Jurisdição constitucional é a função exercida para a proteção e para a manutenção da supremacia constitucional." (BARACHO, 2006, p. 50).

Faz-se também oportuna e adequada a introdução às reflexões pertinentes acerca da função jurisdicional no Estado, a que subsequente se apresenta, perpetuando os ensinamentos de Ronaldo Brêtas de Carvalho Dias, em que afirma

\begin{abstract}
na concepção principiológica e constitucional de Estado Democrático de Direito, [BRÊTAS DE CARVALHO DIAS, 2003, v. 9, p. 230] a chamada função jurisdicional ou simplesmente jurisdição é atividade-dever do Estado, prestada pelos seus órgãos competentes, indicados no texto da Constituição, somente possível de ser exercida sob petição da parte interessada (direito de ação) e mediante a indispensável garantia do devido processo constitucional. [grifos nossos] Em outras palavras, a jurisdição somente pode ser desenvolvida ou prestada por meio de processo instaurado e desenvolvido em forma obediente aos princípios e regras constitucionais, entre os quais avultam o juízo natural, a ampla defesa, com todos os meios e recursos a ela (defesa) inerentes, o contraditório e a fundamentação dos pronunciamentos jurisdicionais com base no ordenamento jurídico vigente (princípio da legalidade ou da reserva legal), com o objetivo de realizar imperativa e imparcialmente o direito. É o que a doutrina italiana chama de modelo constitucional do processo (BRÊTAS DE CARVALHO DIAS, 2006, p. 225).
\end{abstract}

Diante de premissa tão elucidativa, convém apenas maturar o tema, destacando aquilo que lhe é mais relevante.

Confere legitimidade ao exposto, os estudos desenvolvidos na esfera da teoria geral do processo constitucional - diretamente ligados e envolvidos ao tema-, que recolhem na doutrina o entendimento que aponta a jurisdição constitucional (CATTONI DE OLIVEIRA, 2000, v. 3, p. 165) como atividade jurisdicional exercida pelo Estado com o objetivo de tutelar o princípio da supremacia da Constituição e o de proteger os direitos fundamentais da pessoa humana nela estabelecidos, meta esta possível a partir do controle de constitucionalidade das leis ordinárias e dos atos estatais que estivessem em contrariedade aos preceitos constitucionais; perfilhados no exame da matéria jurídico-constitucional em consenso à fixação de uma estrutura de garantias, com mecanismos efetivos, que protegesse e assegurasse a efetividade daqueles direitos.

As garantias processuais constitucionais, reconhecidas também como tutela constitucional do processo (devido processo legal, recurso de amparo, recurso de proteção, recurso constitucional, ação direta de inconstitucionalidade, mandado de segurança, habeas corpus, habeas data, mandado de injunção, ação popular, cada um dentro de suas 
especificidades), definiram o sistema de proteção dos direitos fundamentais, que impõe ao Estado o exercício da jurisdição constitucional para efetivação dos direitos fundamentais em situações concretas, bem como do controle de constitucionalidade das leis ordinárias e dos atos normativos estatais.

Foi a partir de estudos de Mauro Cappelletti (CAPPELLETTI; GARTH, 2002) que se designou os mecanismos processuais dirigidos especificamente à tutela dos direitos fundamentais consagrados na Constituição e os órgãos jurisdicionais encarregados de realizála, como jurisdição constitucional da liberdade; que o autor identifica com justiça constitucional e a considera função jurisdicional de tutela e atuação dos preceitos da Constituição, abrangendo o controle de constitucionalidade das leis e os mecanismos de tutela dos direitos de liberdade do ser humano (BRÊTAS DE CARVALHO DIAS, 2004, p. 91).

No Direito brasileiro divide-se entre jurisdição difusa e jurisdição concentrada, os sistemas que compõem as modalidades de efetivação da jurisdição constitucional. Essa complexa estrutura permite que, por meio da jurisdição difusa, qualquer órgão jurisdicional exerça o controle de constitucionalidade das leis e dos atos normativos de forma concreta e incidental; já na jurisdição concentrada, por sua vez, o mesmo controle de constitucionalidade é atributo exclusivamente ao Supremo Tribunal Federal (STF), mediante provocação das pessoas legitimadas a tanto no texto constitucional, de acordo com o devido processo legal, que aspira um pronunciamento final com eficácia para todos.

A função jurisdicional, no Estado Democrático de Direito, é serviço público dependente de provocações dos interessados, e consiste em cumprir e fazer cumprir as normas do Direito Positivo, realizando o ordenamento jurídico, por meio de um procedimento legalmente estruturado e informado pelos princípios do contraditório e da ampla defesa (BRÊTAS DE CARVALHO DIAS, 2005, v. 8, p. 232). Vale ainda ressaltar que não tem esta atividade cunho caritativo, mas sim, qualifica-se na obrigação consagrada no poder-dever do Estado, que, por este motivo, converte-se em direito fundamental, adquirido pela garantia do devido processo constitucional, a todos da sociedade (governantes e governados).

A partir de tais considerações, pode-se dizer que também nas decisões jurisdicionais, há necessidade da atividade preparatória do pronunciamento com a participação dos afetados em simétrica paridade, permitindo-se a consideração de argumentos de todos (inclusive minorias), em respeito aos direitos e garantias fundamentais, principalmente os elencados explicita e implicitamente na Constituição de 1988, tudo em respeito ao Estado Democrático de Direito. 


\section{AS GRATUIDADES NO NOVO CPC}

As gratuidades constituem medida essencial para se garantir o acesso à jurisdição e não eram tratadas no CPC de 1973, mas pela Lei 1060/50. Assim, o artigo 98 do Código de Processo Civil de 2015 inovou ao determinar um rol de nove itens de custas e despesas processuais que podem ser objeto de gratuidade, a ser declarada pelo juiz, dentre os quais se destaca as custas judiciais, os emolumentos dos notários e registradores, os honorários periciais, as despesas com realização do exame de DNA, dentre outros.

De acordo com o texto legal, o benefício pode ser concedido tanto a pessoas físicas como a pessoas jurídicas, superando a controvérsia quanto à possibilidade de concessão deste benefício às pessoas jurídicas. Contudo, quando se tratar de pessoa física, basta a alegação de hipossuficiência para a concessão da gratuidade, o que pode ser impugnado pela outra parte, ao passo que as pessoas jurídicas devem comprovar a condição.

A respeito da presunção relativa de veracidade da alegação de hipossuficiecia das pessoas naturais, em comparação com as pessoas jurídicas, ensina Ticiano Alves e Silva:

Assim, à pessoa natural basta a mera alegação de insuficiência de recursos, sendo desnecessária a produção de provas da hipossuficiência financeira. A alegação presume-se verdadeira, admitindo-se, contudo, que cesse por prova em contrário produzida pela parte adversa ou em razão de investigação feita de ofício pelo juiz.

Por sua vez, a pessoa jurídica deve comprovar a insuficiência de recursos para fazer jus à gratuidade da justiça, sendo irrelevante possuir finalidade lucrativa ou não. Vale dizer, tanto as pessoas jurídicas com fins lucrativos como as pessoas jurídicas sem fins lucrativos devem demonstrar a insuficiência de recursos para usufruir o benefício da justiça gratuita.

Assim, para as pessoas jurídicas, não se tem a presunção relativa de veracidade da alegação; deve o interessado, pois, alegar e provar a insuficiência de recursos. (SILVA, 2015, p. 14).

Além disso, a gratuidade pode ser concedida tanto para brasileiros como para estrangeiros, residentes ou não no Brasil, conforme expressa redação do caput do artigo 98 do Novo CPC, tendo em vista a universalidade do direito fundamental ao acesso à justiça.

O Novo CPC prevê ainda outras formas de auxílio para a parte hipossuficiente além da gratuidade integral das custas, conforme previsão dos parágrafos quinto e sexto do artigo 98. De acordo com o parágrafo quinto a gratuidade pode ser concedida em relação a algum ou todos os atos processuais ou consistir na redução percentual das despesas processuais. Já o parágrafo sexto autoriza ao juiz conceder o parcelamento das despesas processuais. 
Vale mencionar que a jurisprudencia dos tribunais superiores já apontavam para a possibilidade de gratuidade parcial, conforme concluímos pelas lições ora transcritas:

De fato, é possível que o postulante possa arcar com algumas custas, e não com outras. Assim, pode-se, por exemplo, conceder o benefício para os honorários periciais, quando tal verba suplantar as forças econômicas da parte, e não concedê-lo para o depósito inicial ou as diligências do oficial de justiça. Tal possibilidade, assim como a concessão integral, há de ser feita caso a caso, isto é, demanda análise específica da situação posta em juízo. Neste sentido segue a jurisprudência: "O Judiciário pode conferir apenas em parte o benefício de assistência judiciária, desde que vislumbrada certa possibilidade de se arcar com as despesas processuais" (STJ, 6 ${ }^{\mathrm{a}} \mathrm{T}$., AgRg no Ag ${ }^{\circ}$ 632.839/MG, Rel. Min. Hélio Quaglia Barbosa, j. 28/3/2006, DJ de 15/5/2006, p. 312). (SCHIMDT JUNIOR, 2015, p. 173).

Estas previsões alternativas viabilizam o acesso à justiça sem onerar o Estado, pois concedem às partes melhores condições de pagamento. O Novo Código de Processo Civil, considerando que os notários e registradores exercem a função pública em caráter privado, reconhece a importancia do recebimento dos emolumentos por esses agentes públicos para viablizar o exercício da atividade e, por isso, determinou o pagamento dos emolumentos pela Fazenda Pública.

De acordo com o texto legal, em caso de gratuidade os emolumentos devem ser custeados com recursos alocados no orçamento do ente público e o valor será fixado conforme tabela do tribunal respectivo. Entretanto, caso as condições financeiras do beneficiário da justiça gratuita se alterem e ele tenha recursos para arcar com as despesas do processo nos próximos cinco anos após o fim do processo, deverá ser responsabilizado pelas mesmas.

\section{CONCILIAÇÃO E MEDIAÇÃO}

As formas alternativas de solução de litígios são reconhecidas, atualmente, como importantes ferramentas de pacificação social, sendo meios eficazes de se garantir o acesso à justiça. A Resolução 125 editada pelo Conselho Nacional de Justiça (CNJ) em 29 de novembro de 2010 se coaduna integralmente com as teses ora defendidas, uma vez que preza pelo uso das formas alternativas de solução de conflitos, principalmente a conciliação e a mediação, e visa à solução adequada para os conflitos de acordo com as suas peculiaridades.

A conciliação pelas serventias extrajudiciais constitui, portanto, de uma importante ferramenta de desjudicialização por ser uma faculdade colocada à disposição do jurisdicionado, sem retirar-lhe a opção de acionar o Poder Judiciário e obter uma prestação jurisdicional. Vale 
ressaltar que esta tendência já é percebida com a Lei 11.441 que admite o divórcio, inventário e separação judicial por escritura pública realizados nas serventias notariais e nos consulados brasileiros.

Com efeito, a conciliação pelas serventias extrajudiciais é baseada na Resolução 125 do CNJ que cria uma Política Judiciária Nacional de Tratamento Adequado dos Conflitos de Interesses cujo objetivo é efetivar o princípio constitucional do acesso à Justiça (art. 5º XXXV, Constituição da República) como "acesso à ordem jurídica justa”. A esse respeito é importante ressaltar o princípio da inafastabilidade do poder judiciário, previsão constitucional insculpida no artigo $5^{\circ}, \mathrm{XXXV}$ da $\mathrm{CR} / 88$, segundo a qual é direito de todos ver apreciada pelo Poder Judiciário lesão ou ameaça de lesão a direito seu, princípio este que corrobora e inspira a máxima que todos têm direito a uma tutela efetiva (SENA, 2010, p. 146), tal como pretendido pela Resolução em estudo.

A Política Nacional Tratamento Adequado dos Conflitos de Interesses é abordada por Kazuo Watanabe como forma de enfrentar a "crise de desempenho e a consequente perda de credibilidade" pelo Judiciário decorrentes da sobrecarga excessiva do judiciário. Segundo o qual:

O mecanismo predominantemente utilizado pelo nosso Judiciário é o da solução adjudicada dos conflitos, que se dá por meio de sentença do juiz. E a predominância desse critério vem gerando a chamada "cultura da sentença", que traz como conseqüência o aumento cada vez maior da quantidade de recursos, o que explica o congestionamento não somente das instâncias ordinárias, como também dos Tribunais Superiores e até mesmo da Suprema Corte. Mais do que isso, vem aumentando também a quantidade de execuções judiciais, que sabidamente é morosa e ineficaz, e constitui o calcanhar de Aquiles da Justiça. (WATANABE, 2008, p 14).

Nota-se, portanto, que a conciliação é abordada como meio a ser incentivado nos tribunais pátrios tendo em vista os bons resultados que alcança, sendo o maior deles o desenvolvimento da cultura voltada à paz social. Nesse sentido a Resolução estudada, com o fito de evidenciar o realce dado pelo CNJ à conciliação e à mediação, disciplina que são instrumentos efetivos de pacificação social, solução e prevenção de litígios, e que a sua apropriada disciplina em programas já implementados nos país tem reduzido a excessiva judicialização dos conflitos de interesses, a quantidade de recursos e de execução de sentenças.

Assim, a necessidade de organizar e uniformizar os serviços de conciliação, mediação e outros métodos consensuais de solução de conflitos é recomendada e incentivada isto porque 
são efetivos instrumentos de paz social, e também por reduzir a judicialização dos conflitos, diminuindo o volume de processos que se acumulam nas varas e tribunais brasileiros.

Ademais, considerando que o tempo é um forte obstáculo ao acesso à jurisdição, ao conciliar existe a satisfação imediata das pretensões da parte e ainda um resultado mediato, qual seja, a redução de demandas a serem apreciadas pelo Judiciário, favorecendo, assim, o acesso à jurisdição aos demais jurisdicionados.

Ainda no que se refere ao acesso à jurisdição, corrobora a Resolução 125 a necessidade de sua garantia em sentido material ao "assegurar a todos o direito à solução dos conflitos por meios adequados à sua natureza e peculiaridade”. Pretendendo, portanto, garantir aos jurisdicionados um aparato que satisfaça seus direitos, prezando pela eficiência e adequabilidade dos meios utilizados para a solução da controvérsia.

A diretriz a ser seguida, portanto, de acordo com a Resolução estudada é a de incentivar a autocomposição dos litígios, devendo os tribunais "desenvolver conteúdo programático mínimo e ações voltadas à capacitação em métodos consensuais de solução de conflitos, para servidores, mediadores, conciliadores e demais facilitadores da solução consensual de controvérsias" (Resolução 120 do CNJ).

Portanto, visa a Resolução 125 do CNJ, precipuamente, que a resposta dada pelo judiciário ao jurisdicionado seja adequada ao conflito de interesses colocado sob análise, o que garante o efetivo exercício do direito ao acesso à jurisdição. Nesse compasso, surge a conciliação como meio garantidor de uma solução célere, justa e, por conseguinte, adequada para recompor o litígio.

É a conciliação uma forma alternativa bastante eficiente na solução de controvérsias, uma vez que, ao chegarem as partes a um ponto comum, são elas capazes de dirimir a lide em seus diversos aspectos, como por exemplo, jurídico, sociológico e psicológico. Assim, ao resolver a lide em todas as suas esferas, alcança a conciliação um patamar de pacificação social inatingível pelos demais meios de solução de conflitos, principalmente pela imposição unilateral da sentença.

Ao conciliar, é possível às partes recompor aquela relação em nível de apaziguamento ${ }^{5}$, alcançando, assim, o escopo social do processo, qual seja, a paz social.

\footnotetext{
${ }^{5}$ Segundo Adriana Goulart Sena, a conciliação significa "entendimento, recomposição de relações desarmônicas, empoderamento, capacitação, desarme de espírito, justamento de interesses. Em dizer psicanalítico: apaziguamento.” (SENA, 2016).
} 
De acordo com José Roberto Freire Pimenta, a conciliação atua, concomitantemente, no planto qualitativo, por recuperar faixas contenciosas não alcançadas por outras formas de resolução de conflitos, efetivando, assim, a tutela jurisdicional, e no plano quantitativo, ao atenuar o número de processos judiciais, reduzindo o tempo médio de tramitação dos demais processos por estarem os órgãos judiciais menos assoberbados (PIMENTA, 2001, p. 155).

Aliás, cumpre citar os escopos do processo identificados por Cândido Rangel Dinamarco, a saber, os escopos sociais que pretendem a pacificação social mediante a eliminação de conflitos com critérios calcados na Justiça, e, como conseqüência, a conscientização dos jurisdicionados para identificar e buscar seus direitos confiando no Poder Judiciário, os escopos políticos com a 'afirmação da capacidade estatal de decidir imperativamente (jurisdição-poder)" e o escopo jurídico de fazer cumprir o preceito legal ao efetivar o direito material (DINAMARCO, 2013, p. 166).

Em relação ao escopo social, é importante frisar que para o acesso à jurisdição ser completo não basta a resolução adequada do conflito garantida pelo Judiciário, é essencial que o jurisdicionado tenha ciência do direito que busca, os riscos que envolvem a demanda e o resultado obtido, entendendo o processo e manifestando livre e conscientemente a sua vontade ao conciliar. Assim, não basta uma resposta célere e efetiva das varas e tribunais, é importante que o cidadão entenda porque tem direito e o que lhe está sendo garantido naquele ato processual.

Ao seu turno, a conciliação se mostra capaz de alcançar também as finalidades política e jurídica, uma vez que a solução encontrada confere credibilidade ao Estado, incentiva aos jurisdicionados a pleitearem seus direitos e, concomitantemente, fortalece o direito por torná- lo efetivo e célere.

Assim, ao realizar os três escopos acima identificados, atinge a conciliação o seu objetivo precípuo de garantir aos jurisdicionados o acesso material à jurisdição, obtendo uma resposta do Judiciário célere e hábil a pacificar com justiça.

A conciliação e a mediação se aproximam na medida em que constituem importantes formas alternativos de solução de conflitos e se distinguem na medida em que na conciliação o terceiro apresenta uma postura ativa, de sugerir propostas que podem ou não ser aceitas pelas partes, ao passo que o mediador teve apenas intermediar o diálogo, sem, contudo, propor qualquer alternativa para o conflito. A mediação, assim como a conciliação, é reconhecida como importante instrumento de pacificação social, pois cumpre todos os misteres acima destacados: 
$\mathrm{Na}$ atualidade a mediação começa a ser um mecanismo mais comum nos programas de resolução alternativa das disputas, uma opção democrática e pedagógica para a intervenção de terceiros nos conflitos. Mas para entender bem a mediação é preciso elaborar uma clara compreensão do que entende por conflito. Qualquer teoria da mediação resta inadequada e insuficiente se não tem por base uma explícita teoria do conflito. (TRENTIN, 2011).

O novo diploma processual reconhece a eficácia das formas alternativas de solução de conflitos e determina no artigo $2^{\circ}, \S 3^{\circ}$, que "a conciliação, a mediação e outros métodos de solução consensual de conflitos deverão ser estimulados por juízes, advogados, defensores públicos e membros do Ministério Público, inclusive no curso do processo judicial” (BRASIL, 2015).

Em alguns estados do país, como por exemplo Maranhão e São Paulo, as serventias notariais e registrais são responsáveis por realizar conciliação e mediação, nos moldes da Resolução 125 do CNJ, contribuindo, assim, para a desjudicialização e facilitando o acesso à jurisdição, tudo em total coerência com as premissas do Novo Código de Processo Civil.

\section{CONCLUSÃO}

Da teoria constitucionalista do processo, colhe-se que o processo, em seus novos contornos teóricos na pós-modernidade, apresenta-se como instituição constitucionalizada que, pela principiologia constitucional do devido processo (que abarca os princípios da reserva legal, da ampla defesa, da isonomia e do contraditório) converte-se em direito-garantia. O conceito contemporâneo de Estado Democrático de Direito exige que o legislador, nas sociedades Políticas Democráticas de Direito, uma vez eleito, submeta-se aos princípios do Processo como instituição jurídica balizadora da soberania popular e da cidadania, cujos fundamentos se assentam no instrumento da jurisdição constitucional e esta como atividade judicatória dos juízes, de forma legal, preexistente e básica, como única fonte do poder constituinte. Assim, não é demais reprisar que o processo constitucional tem por fundamento garantir o princípio da supremacia constitucional, possibilitando a efetiva tutela, proteção e fomento dos direitos fundamentais.

Importante ressaltar que o processo constitucional demanda pressupostos essenciais, dentre eles: o direito à celeridade dos processos, a razoável duração dos pleitos, e as formas de controle constitucional (preventivo, repressivo, direto, repressivo indireto e ocasional); que não podem ser confundidos com diminuição ou eliminação das garantias processuais 
constitucionais (contraditório, ampla defesa, duplo grau de jurisdição, fundamentação das decisões, direito de prova, instrumentalidade das formas, presença de advogado, dentre outros), sob pena de ferir o princípio do Estado Democrático de Direito.

À jurisdição constitucional define-se como atividade jurisdicional exercida pelo Estado com o objetivo de tutelar o princípio da supremacia da Constituição e a proteção aos direitos fundamentais da pessoa humana nela estabelecidos. Meta possível a partir do controle (difuso e concentrado) de constitucionalidade das leis ordinárias e dos atos estatais que estejam em contrariedade aos preceitos constitucionais; perfilhados no exame da matéria jurídicoconstitucional em consenso à fixação de uma estrutura de garantias (devido processo legal, recurso de amparo, recurso de proteção, recurso constitucional, ação direta de inconstitucionalidade, mandado de segurança, habeas corpus, habeas data, mandado de injunção, ação popular, cada um dentro de suas especificidades), com mecanismos efetivos, que proteja e assegure a efetividade daqueles direitos.

Assim, superar os obstáculos do acesso à jurisdição é um dos desafios do Novo Código de Processo Civil, o qual inova ao disciplinar as gratuidades (primeiro obstáculo reconhecido pelos autores estudados), bem como ao fomentar a utilização de formas alternativas de solução de conflitos.

Para que a tutela jurisdicional seja efetiva é necessário, em muitos casos, que as decisões sejam levadas a registro, momento a partir do qual ganham publicidade e são oponíveis perante terceiros. As gratuidades, conforme demonstrado, podem ser integrais ou apenas facilitar o pagamento das custas, mediante parcelamento ou desconto percentual, para que os benefícios concedidos sejam proporcionais à realidade econômica das partes.

Ademais, a realização de conciliação e mediação pelas serventias extrajudiciais, nos moldes da Resolução 125 do CNJ, também se coaduna com a ideologia do Novo CPC, que prevê expressamente que as mesmas devem ser incentivadas.

Portanto, as serventias notariais e de registro são importantes ferramentas de desjudicialização, pois colocam à disposição dos cidadãos uma via alternativa de solução dos conflitos, sem necessidade de acionar o Judiciário, com a efetivação dos elevados preceitos constitucionais do Estado Democrático de Direito.

\section{REFERÊNCIAS}

BARACHO, José Alfredo de Oliveira. Processo constitucional. Rio de Janeiro: Forense, 1984. 
BARACHO, José Alfredo de Oliveira. Direito processual constitucional: aspectos contemporâneos. Belo Horizonte: Fórum, 2006.

BRASIL. Altera a Lei n⿳ 13.105, de 16 de março de 2015 (Código de Processo Civil), para disciplinar o processo e o julgamento do recurso extraordinário e do recurso especial, e dá outras providências. Lei 13.256, de 4 de fevereiro de 2016. Disponível em:

<http://www.planalto.gov.br/ccivil_03/_ato2015-2018/2016/Lei/L13256.htm\#art2>. Acesso em: 30 mar. 2016.

BRASIL. Código de Processo Civil. Lei 5.869, de 11 de janeiro de 1973. Disponível em: <http://www.planalto.gov.br/ccivil_03/leis/L5869.htm>. Acesso em: 30 mar. 2016.

BRASIL. Código de Processo Civil. Lei 13.105, de 16 de março de 2015. Disponível em: <http://www.planalto.gov.br/ccivil_03/Decreto-Lei/Del3689.htm>. Acesso em: 30 mar. 2016. BRASIL. Constituição da República Federativa do Brasil de 1988. Disponível em: <http://www.planalto.gov.br/ccivil_03/Constituicao/Constituicao.htm>. Acesso em: 30 mar. 2016.

BRASIL. Supremo Tribunal Federal. ADC 5, Rel. Min. Ricardo Lewandowski, julgamento em 11-6-2007, Plenário, DJ de 5-10-2007.

BRASIL. Supremo Tribunal Federal. ADI 1.444, Rel. Min. Sydney Sanches, julgamento em 12-2-2003, Plenário, DJ de 11-4-2003.

BRASIL. Supremo Tribunal Federal. ADI 1.800, Rel. p/ o ac. Min. Ricardo Lewandowski, julgamento em 11-6-2007, Plenário, DJ de 28-9-2007.

BRASIL. Supremo Tribunal Federal. ADI 3.643, voto do Rel. Min. Ayres Britto, julgamento em 8-11-2006, Plenário, DJ de 16-2-2007.

BRÊTAS DE CARVALHO DIAS, Ronaldo. Responsabilidade do Estado pela função jurisdicional. Belo Horizonte: Del Rey, 2004.

BRÊTAS DE CARVALHO DIAS, Ronaldo. Direito à jurisdição eficiente e garantia da razoável duração do processo na reforma do judiciário. Revista da Faculdade Mineira de Direito, v. 8, n. 15 , Belo Horizonte, $1^{\circ}$ sem./2005.

CAPPELlETTI, Mauro; GARTH, Bryant. Acesso à justiça. Porto Alegre: Sérgio Antônio Fabris, 2002.

CATTONI DE OLIVEIRA, Marcelo Andrade. O processo constitucional como instrumento da jurisdição constitucional. Revista da Faculdade Mineira de Direito, v. 3, ns. 5 e $6,1^{\circ}$ e $2^{\circ}$ sem./2000.

CATTONI DE OLIVEIRA, Marcelo Andrade. Devido processo legislativo. 2. ed. Belo Horizonte: Mandamentos, 2006. 
DIDIER JR., Freddie; PEIXOTO, Ravi Medeiros. Novo Código de Processo Civil - Estudo comparativo com o Código de 1973. Salvador: JusPodivm, 2015.

DINAMARCO, Cândido Rangel. A instrumentalidade do processo. 15. ed. São Paulo: Malheiros, 2013.

GIGLIO, Wagner D. A Conciliação nos Dissídios Individuais do Trabalho. São Paulo: LTr, 1982.

GONÇALVES, Aroldo Plínio. Técnica processual e teoria do processo. Rio de Janeiro: Aide, 2001.

GUSTIN, Miracy Barbosa de Sousa; DIAS, Maria Tereza Fonseca Dias. (Re)pensando a pesquisa jurídica: teoria e prática. Belo Horizonte: Del Rey, 2006.

LEAL, Rosemiro Pereira. Processo e Hermenêutica Constitucional a partir do Estado de Direito Democrático. In: LEAL, Rosemiro Pereira (Coord.). Estudos continuados de teoria do processo. 4. ed. Porto Alegre: Síntese, 2001, v. 2, 2004, v. 5, 2005, v. 6.

MAZZA, Alexandre. Manual de Direito Administrativo. 4. ed. São Paulo: Saraiva, 2014.

NICACIO, Camila Silva. Mediação para a autonomia, alteridades em diálogo. In: DIAS, Maria Tereza Fonseca (Org.). Mediação, cidadania e emancipação social. Belo Horizonte: Fórum, 2010 .

PIMENTA, José Roberto Freire. A Conciliação judicial na Justiça do Trabalho após a Emenda Constitucional n. 24/99: aspectos de direito comparado e o novo papel do juiz do trabalho. São Paulo. Revista LTr, vol. 65, no. 02, fevereiro de 2001, p.155.

RODRIGUES, Marcelo. Tratado de Registros Públicos. São Paulo: Atlas, 2014.

SENA, Adriana Goulart. Juízo Conciliatório Trabalhista. Disponível em: < http://www.trt3.jus.br/escola/download/revista/rev_75/Adriana_Sena.pdf>. Acesso em: 30 mar. 2016.

SILVA, Ticiano Alves e. O beneficiário da gratuidade da justiça no novo CPC. Portal Processual: Direito Processual Civil. Disponível em: <http://portalprocessual.com/obeneficiario-da-gratuidade-da-justica-no-novo-cpc/>. Acesso em: 30 mar. 2016.

THEODORO JR, Humberto Teodoro et al. Novo CPC - Fundamentos e sistematização. 2 ed. Ver. Atual. e ampl. Rio de Janeiro: Forense, 2015.

TRENTIN, Taise Rabelo Dutra; TRENTIN, Sandro Seixas. Mediação como um meio alternativo de tratamento de conflitos prevista no novo CPC e na Resolução 125 CNJ. In: Âmbito Jurídico, Rio Grande, XIV, n. 95, dez 2011. Disponível em: <http://ambitojuridico.com.br/site/?artigo_id=10863\&n_link=revista_artigos_leitura>. Acesso em: 30 mar. 2016. 
WATAnABE, Kazuo. Modalidades de Mediação. Série Cadernos do CEJ, n. 22, Brasília: Conselho da Justiça Federal, 2001.

Watanabe, Kazuo. Política Pública do Poder Judiciário: tratamento adequado dos conflitos de interesses. Disponível em: <http://www.cnj.jus.br/images/programas/movimentopela-

conciliacao/arquivos/cnj_portal_artigo_\%20prof_\%20kazuo_politicas_\%20publicas.pdf>. Acesso em: 30 mar. 2016. 